\title{
Aqueous morpholine pre-treatment in cellulose nanofibril (CNF) production: comparison with carboxymethylation and TEMPO oxidisation pre-treatment methods
}

\author{
Amaka J. Onyianta $($ D $\cdot$ Mark Dorris $\cdot$ Rhodri L. Williams
}

Received: 18 September 2017/Accepted: 15 December 2017/Published online: 21 December 2017

(C) The Author(s) 2017. This article is an open access publication

\begin{abstract}
In this study, pulped cellulose fibres were pre-treated with aqueous morpholine prior to mechanical disruption in the production of cellulose nanofibrils (CNF). The properties of the morpholine pretreated CNF (MCNF) were closely compared with CNF obtained from carboxymethylation (CMCNF) and TEMPO-oxidation (TCNF) pre-treatment methods. An investigation of the swelling behaviours of cellulose in varying concentrations of morpholine revealed that there is a synergistic behaviour between morpholine and water in its ability to swell cellulose. As a result, cellulose pulp dispersed in 1:1 mole ratio of morpholine to water was well swollen and readily fibrillated by mechanical shear. Surface chemistry analyses indicated that the surface of the MCNF remained unmodified, compared to the CMCNF and TCNF which were modified with anionic groups. This resulted in only a slight decrease in crystallinity index and a minimal effect on the thermal stability of MCNF, compared to $\mathrm{CMCNF}$ and $\mathrm{TCNF}$ which showed marked decreases in crystallinity indices and thermal
\end{abstract}

A. J. Onyianta $(\bowtie) \cdot$ M. Dorris · R. L. Williams

Material Chemistry and Processing, School of

Engineering and Built Environment, Edinburgh Napier

University, Edinburgh EH10 5DT, UK

e-mail: a.onyianta@napier.ac.uk

M. Dorris

e-mail: m.dorris@napier.ac.uk

R. L. Williams

e-mail: dr.rlwilliams@btinternet.com stabilities. The average widths of MCNF, CMCNF and TCNF, as measured from electron microscopic images, were broadly similar. The higher polydispersity of MCNF widths however led to a differential sedimentation and subsequent lower aspect ratio in comparison with CMCNF and TCNF as estimated using the sedimentation approach. Also, the presence of electrostatic repulsive forces, physical interactions/ entanglements and lower rigidity threshold of the CMCNF and TCNF resulted in higher storage moduli compared to the MCNF, whose elasticity is controlled by physical interactions and entanglements. Aqueous morpholine pre-treatment can potentially be regarded as an ecologically sustainable process for unmodified CNF production, since the chemical reagent is not consumed and can be recovered and reused.

Keywords Cellulose nanofibrils (CNF) . Morpholine pre-treatment - Carboxymethylation . TEMPO-oxidation - Surface modification . Mechanical fibrillation $\cdot$ Sedimentation

\section{Introduction}

Cellulose nanofibrils (CNF), alongside cellulose nanocrystals and bacterial nanocellulose, are the three types of nanocellulose that have been identified in literature (Abdul Khalil et al. 2014; Bharimalla et al. 
2015; Jonoobi et al. 2015; Klemm et al. 2011; Lavoine et al. 2012; Nechyporchuk et al. 2016a; Siró and Plackett 2010). CNF can be derived from cellulose fibres by a combination of mechanical, enzymatic, and chemical pre-treatment steps prior to mechanical processing (Nechyporchuk et al. 2016a). There has been considerable industrial and research interest in the use of CNF in a wide range of applications, such as in biomedicine (Guise and Fangueiro 2016; Lin and Dufresne 2014), automotive exteriors and interiors (Faruk et al. 2014), packaging materials (Ferrer et al. 2017; Li et al. 2015) and electronic devices (Du et al. 2017; Shi et al. 2013). This wide usage arises because of their renewability, biocompatibility and biodegradation potentials coupled with improved mechanical strength, lightweight properties, optical properties, barrier properties and structuring capabilities (Abdul Khalil et al. 2014; Bharimalla et al. 2015; Jonoobi et al. 2015; Klemm et al. 2011; Lavoine et al. 2012; Siró and Plackett 2010). Moreover, the cellulose starting material, which is the most abundant polymer on earth, provides potential for sustainable low-cost products.

The presence of 3 hydroxyl groups on each $\beta$-Danhydroglucopyranose repeat unit of cellulose (French 2017) brings about intramolecular, intermolecular and hydrophobic forces that must be overcome, usually by any method that induces fibre swelling, in order to open up the cellulose structure and more easily liberate the nano-sized fibrils within (Nechyporchuk et al. 2016a). Water has been the most used swelling agent for cellulose, hence the first reported method for the production of CNF involved the dispersion of cellulose fibre in aqueous medium to prepare a slurry (Turbak et al. 1983a, b). The slurry was delaminated into microfibrils via homogenisation under high pressure and high shear velocity, a process made possible by the increase in water-dependent swelling of the initial cellulose fibres. If discrete monodisperse nanofibrils were to be produced however, the homogenisation process must be repeated for up to 20-50 times (Spence et al. 2011; Taheri and Samyn 2016), thereby leading to high energy consumption with prohibitive costs.

In order to reduce this high energy consumption, various pre-treatment methods have been studied and reviewed. These could be categorised into mechanical processes (e.g. beating, refining, milling) (Spence et al. 2011), enzymatic pre-treatment (Pääkkö et al.
2007), and chemical pre-treatments. Mechanical processes or enzymatic pre-treatments do not lead to surface modification of cellulose fibres. Some of the chemical pre-treatment methods that have been investigated include carboxymethylation (Naderi et al. 2014; Wågberg et al. 2008), 2,2,6,6-tetramethylpiperidine-1-oxyl (TEMPO)-mediated oxidation (Isogai et al. 2011; Saito and Isogai 2004; Saito et al. 2007), periodate-chlorite oxidation (Liimatainen et al. 2012), periodate-bisulphite treatment (Liimatainen et al. 2013) and quaternisation (Abbott et al. 2006; Aulin et al. 2010). These are all aimed at substituting the hydroxyl groups on cellulose with either negatively charged or positively charged moieties. It has been shown that the presence of the charged groups bring about electrostatic repulsion and fibre swelling which reduces the effect of hydrogen bonding and hydrophobic interactions, thereby easing fibrillation (Nechyporchuk et al. 2016a). In addition, a multicomponent microemulsion system containing either urea or ethylenediamine was used to ease the delamination of cellulose and lignocellulosic fibres (Carrillo et al. 2014). The authors attributed the reduction in energy demand for CNF production to the ability of the microemulsion system to reduce the hydrogen bonding effect on cellulose. However, the effect of this treatment on the surface functionality of the resulting CNF was not studied. Switchable ionic liquid has also been used with the same aim of facilitating cellulose delamination into CNF material (Berglund et al. 2017).

These chemical pre-treatment methods often lead to reduction in crystallinity index and thermal stabilities of the resulting CNF (Fukuzumi et al. 2010; Lavoine et al. 2016). For example, Eyholzer et al. (2010) showed a $31 \%$ decrease in crystallinity index of CNF after carboxymethylation pre-treatment followed by mechanical processing. This reduction in crystallinity index could potentially affect the reinforcing capability when used in composite materials. Another major concern with these chemical pre-treatments is the consumption of large amounts of associated chemicals, which show minimal potential for recycling, and are often associated with high cost. Indeed, efforts have been made to recover hypochlorite and TEMPO from the reaction mixtures by electrolysis and solid phase extraction (Kuutti et al. 2016). However, the inclusion of such recycling lines to the main production line may come at an extra cost and so striking the 
right balance between recycling of chemicals and use of fresh chemicals becomes imperative. Otherwise, the overall cost of the pre-treatment process could nullify any benefits accrued from a reduction in energy consumption (Bharimalla et al. 2015).

Depending on the intended application of the CNF, a post modification process may be required to impart various surface functionalities to the $\mathrm{CNF}$ or to graft the CNF onto a polymer matrix (Missoum et al. 2013). Chemical pre-treatment methods which modify the surface of CNF with either positive or negative charges are most suitable for post-modification by adsorption with molecules having complementary charges (Missoum et al. 2013). Therefore, having a CNF starting material whose surface is uncharged would allow for the attachment of different functionalities, using the cellulose hydroxyl groups to provide reactive sites for modification (Deng et al. 2016; Eyley and Thielemans 2014; Missoum et al. 2013).

Morpholine $\left(\mathrm{C}_{4} \mathrm{H}_{9} \mathrm{NO}\right)$ is an organic solvent which is completely miscible with water. Betrabet, Lokhande and co-workers investigated the use of aqueous morpholine and other amines as swelling agents for cotton to increase its dye uptake (Betrabet et al. 1966; Betrabet and Rollins 1970; Kulkarni and Lokhande 1975; Lokhande 1978; Lokhande et al. 1984). They observed that aqueous morpholine can swell cotton cellulose without changing its density, crystallinity index and tensile strength (Betrabet et al. 1966; Betrabet and Rollins 1970). It was then concluded that morpholine is an inter-crystalline swelling agent, which can access the disordered regions of cellulose without bringing about any derivatisation. Likewise, Paul and Teli (2011) reported an increase in the ability of enzymes to access cellulose when treated with $40 \%$ aqueous morpholine compared to the untreated cellulose (Paul and Teli 2011). In a Patent by Graveson and English (2015), morpholine was one of the swelling agents used to facilitate the fibrillation of cellulose to produce cellulose nanofibrils. However, it is not clear how the properties of the CNF produced by the morpholine pre-treatment compare to the properties of CNF from other chemical pre-treatments.

In this study, the properties of cellulose nanofibrils produced after aqueous morpholine pre-treatment were investigated and compared with the properties of carboxymethylated and TEMPO-oxidised cellulose nanofibrils. The swelling behaviour of cellulose in various concentrations of morpholine in water was initially studied by swelling experiments to determine the extent of swelling and to identify the optimum concentration range. The possible surface modification of the cellulose after the pre-treatments was investigated by conductometric titration and Fourier transform infrared spectroscopy (FTIR). Changes in crystallinity index and thermal stability as a result of the chemical pre-treatment and mechanical processing were examined by X-ray diffraction (XRD) and thermogravimetric analysis (TGA). Field emission scanning electron microscopic (FE-SEM) images and transmission electron microscopic (TEM) images were used for the assessment of fibril widths and morphology. The estimation of aspect ratio by connectivity threshold analysis using sedimentation, which has been applied on uncharged CNFs (Raj et al. 2016; Varanasi et al. 2013; Zhang et al. 2012) was extended to CNF with surface charges, by taking advantage of the screening effect of salt medium on charged CNF. Finally, the viscoelastic properties of the aqueous suspensions of the CNFs were studied.

\section{Experimental}

\section{Materials}

Commercial grade of never-dried hardwood bleached sulphite cellulose pulp (32 wt\% solid content) was received from Sappi Ltd (South Africa) and used for all the pre-treatments. Microcrystalline cellulose (MCC, Avicel PH-101), morpholine, monochloroacetic acid, sodium hydroxide $(\mathrm{NaOH})$, Isopropanol, ethanol, methanol, acetic acid, sodium bicarbonate $\left(\mathrm{NaHCO}_{3}\right)$, hydrogen chloride $(\mathrm{HCl})$, sodium chloride $(\mathrm{NaCl})$ were all analytical grade and used as received from Sigma Aldrich (United Kingdom). Ultrapure water (Purelab Option-Q ELGA DV 25) was used throughout the experiments.

Morpholine pre-treatment

\section{Swelling study}

A swelling study was first carried out on MCC using varying concentrations of aqueous morpholine to observe the swelling behaviour of the microcrystalline cellulose. $9 \mathrm{~mL}$ of morpholine swelling agent with varying concentrations in mole fraction was added to 
$1 \mathrm{~g}$ of MCC in individual $15 \mathrm{~mL}$ glass vial. The resulting dispersions were shaken vigorously and allowed to equilibrate for $24 \mathrm{~h}$ before photographs were captured using a Sony HX60 digital camera. The heights of the swollen cellulose and the total heights of the dispersion were measured using ImageJ software. The relative height of the swollen cellulose and the swelling index, which facilitates comparison relative to swelling in pure water, were calculated using the relationships below.

$h_{r}=h_{c} / h_{0}$

$S I=h_{r}($ swelling agent $) / h_{r}($ water $)$

here $h_{r}$ is relative height of cellulose, $h_{c}$ is height of cellulose, $h_{0}$ is total height of dispersion and $S I$ is the swelling index.

An average of three experiments was used to plot the mole fraction of morpholine to water against the swelling index of MCC.

\section{Production of CNF from morpholine pre-treatment}

Never-dried cellulose pulp was dispersed in 1:1 mole ratio or 0.5 mole fraction of morpholine to water (83 wt\%) using T25 digital Ultra Turrax disperser (Ika, Germany) for $10 \mathrm{~min}$ at $10,000 \mathrm{rpm}$ to make a $1 \mathrm{wt} \%$ slurry. The slurry was allowed to swell for $168 \mathrm{~h}$, after which it was passed 5 times through the $200 \mu \mathrm{m}$ auxiliary chamber and $100 \mu \mathrm{m}$ Z-shaped interaction chamber of the M-110EH high pressure homogeniser (Microfluidics, USA) at 172.4 MPa. The fibrillated cellulose in aqueous morpholine was washed by 10 centrifugation cycles at $10,000 \mathrm{rpm}$ and 15 min per cycle. The first supernatant obtained from centrifugation (purely aqueous morpholine swelling agent) can potentially be used for another swelling regime. A $1 \mathrm{wt} \%$ aqueous dispersion of the fibrillated cellulose was passed once through the $200 \mu \mathrm{m}$ auxiliary chamber of the high pressure homogeniser to effectively disperse the fibril aggregates caused by centrifugation. The resulting CNF, herein called MCNF was stored in the refrigerator, whilst a small proportion was freeze-dried (VirTis benchtop freeze dryer, SP Scientific, USA).
Carboxymethylation and TEMPO-oxidation pretreatments

Carboxymethylation was carried out on the neverdried cellulose pulp using the procedures described by Wågberg et al. (2008), while the general procedure described by Saito and Isogai (2004) for TEMPOoxidation was adopted using the same starting material. Aqueous dispersions (1 wt $\%)$ of the carboxymethylated and TEMPO-oxidised cellulose were prepared from the insoluble cellulose, in sodium form, obtained after the pre-treatments and passed 5 times through the high pressure homogeniser using the same conditions as with the morpholine pre-treatment. The resulting CNFs, herein called CMCNF for the carboxymethylated CNF and TCNF for the TEMPOoxidised CNF were stored in the refrigerator, whilst small proportions were freeze-dried. All samples were characterised at $1 \mathrm{wt} \%$ solid content in aqueous media or freeze dried, except where stated otherwise.

Total surface charge determination

The total surface charge of the never-dried cellulose, morpholine pre-treated cellulose and carboxymethylated cellulose were determined by conductometric titration according to the SCAN-CM 65:02 method (Total acidic group content 2002). In summary, cellulose samples were each dispersed in $0.1 \mathrm{M} \mathrm{HCl}$ and allowed to stand for $15 \mathrm{~min}$ before being washed until the conductivity was less than $5 \mu \mathrm{S} / \mathrm{cm}$. Then $490 \mathrm{~mL}$ of ultrapure water and $10 \mathrm{~mL}$ of $0.05 \mathrm{M} \mathrm{NaCl}$ were added to $0.5-1 \mathrm{~g}$ dry weight of cellulose pulp in a beaker. This was stirred thoroughly using a magnetic stirrer and titrated against $0.05 \mathrm{M} \mathrm{NaOH}$. The total surface charge on the TEMPO-oxidised cellulose was measured using the method described by Saito and Isogai (2004). The total surface charge was determined from the analysis of the conductivity curve using OriginPro 2017 software (OriginLab Corporation, USA).

Fourier transform infrared spectroscopy (FTIR) analysis

The surface chemistry of the cellulose pulp starting material and the pre-treated cellulose were analysed from freeze-dried sample using Spectrum 100 FTIR (Pelkin Elmer, USA) in the ATR mode. Spectral data 
was collected after 8 scans from 4000 to $450 \mathrm{~cm}^{-1}$ wavenumber.

\section{$\mathrm{X}$-ray diffraction $(\mathrm{XRD})$}

The impact of the pre-treatments and mechanical treatment on the cellulose was investigated by crystallinity index measurement collected from X-ray diffractograms of the freeze-dried samples. The samples were measured in reflection mode, using a vertical $\theta-\theta$ Bragg-Brentano diffractometer D5000 (Siemens Bruker, Gmbh) with $\mathrm{Cu} \mathrm{K} \alpha \mathrm{X}$-ray source. $2 \theta$ scans were performed from $5^{\circ}$ to $50^{\circ}$, in $0.05^{\circ}$ increments, with rotation of the holders about the phi axis. Cellulose crystallinities were determined by subtracting an amorphous background from the samples' XRD profiles. The crystallinity indices $(\mathrm{Cr})$ were calculated using Eq. 3.

$C r I=\left(\frac{I_{200}-I_{a m}}{I_{200}}\right) \times 100$

where $I_{200}$ is the maximum intensity at $2 \theta=22.5^{\circ}$, corresponding to the (200) diffraction lattice, and $I_{a m}$ is the intensity of the amorphous region with diffraction angle of $2 \theta=18.5^{\circ}$.

\section{Thermogravimetric analysis (TGA)}

Freeze-dried cellulose starting material and the pretreated CNFs were thermogravimetrically analysed using Mettler Toledo TGA/DSC1 Star System (Mettler Toledo, Switzerland). 8 to $8.5 \mathrm{mg}$ of samples were heated from 25 to $600{ }^{\circ} \mathrm{C}$ at a constant heating rate of $10{ }^{\circ} \mathrm{C} / \mathrm{min}$ under a constant nitrogen flow of $80 \mathrm{~mL} /$ $\min$.

\section{Morphological assessments}

FE-SEM micrographs were acquired from all the pretreated samples using FE-SEM S-4800 (Hitachi, Japan). Prior to analysis, $20 \mu \mathrm{L}$ of $0.0005 \mathrm{wt} \%$ slurry was deposited on the mica surface on the SEM stub and left overnight to air dry. This was sputter coated with a layer of gold for $85 \mathrm{~s}$ using EMITECH K550X (Quorumtech, UK) gold sputter coater. TEM images were acquired at $80 \mathrm{kV}$ using Zeiss Leo EM900 (Carl Zeiss, AG) after staining $0.01 \mathrm{wt} \% \mathrm{CNF}$ samples with $1.5 \%$ phosphostungstic acid and air dried for $24 \mathrm{~h}$. The fibril widths from both FE-SEM and TEM images of all the pre-treated CNFs were measured using ImageJ software. Fibril width distributions were obtained from measurements on at least 150 fibrils.

Sedimentation

The theory, methods and equations for the determination and calculation of connectivity threshold $\left(\Phi_{c}\right)$ and rigidity threshold of CNF from sedimentation experiments have been well described by Zhang et al. (2012), Varanasi et al. (2013) and Raj et al. (2016). The connectivity threshold is defined as "the boundary between the dilute and semi-dilute regions, the lowest volume fraction where the particles first form a continuous network" (Varanasi et al. 2013). The connectivity threshold can be determined experimentally by fitting the plot of initial concentration of CNF vs relative sediment height with a quadratic regression, where the linear term of the regression is equivalent to the connectivity threshold (Zhang et al. 2012). The rigidity threshold on the other hand is the boundary between the semi-dilute and concentrated regions, the threshold at which the fibres first begin to contribute to mechanical strength. The rigidity threshold is 4 times the connectivity threshold (Celzard et al. 2009; Varanasi et al. 2013).

Prior to the sedimentation experiments, all the pretreated samples were dispersed in a range of 0 to $4 \mathrm{M}$ $\mathrm{NaCl}$ at $0.07 \mathrm{w} / \mathrm{v} \%$. This was done to identify the effect of salt medium on the pre-treated samples and to examine the charge screening potentials of different concentrations of salt on CMCNF and TCNF. Subsequently, 2 and $3 \mathrm{M} \mathrm{NaCl}$ solution was chosen as the medium for the sedimentation of the CMCNF and TCNF samples respectively. These salt concentrations represent an average salt concentration where a plateau in the relative sediment heights were attained. The morpholine pre-treated sample was prepared in aqueous medium as the different salt concentrations showed no difference in the relative sediment height. Suspensions for sedimentation were prepared from $1 \mathrm{wt} \%$ original aqueous suspensions of the CNF samples between solid concentrations of $0.01-0.1 \mathrm{wt} \%$. These were allowed to sediment in $60 \mathrm{~mL}$ glass vials for $96 \mathrm{~h}$ before photographs were captured. The sediment heights $\left(h_{s}\right)$ and the initial suspension heights $\left(h_{0}\right)$ were measured using Image J software from the photographic images. The plot of 
concentration (wt \%) against the relative sediment height $\left(h_{s} / h_{0}\right)$ was fitted with the quadratic equation $\left(a x^{2}+b x\right)$, where the linear fit parameter $b$, is equal to the connectivity threshold (Zhang et al. 2012).

Using the densities of water $\left(1 \mathrm{~g} / \mathrm{cm}^{3}\right), 1.83 \mathrm{M}$ $\mathrm{NaCl}\left(1.07 \mathrm{~g} / \mathrm{cm}^{3}\right), 3.06 \mathrm{M} \mathrm{NaCl}\left(1.11 \mathrm{~g} / \mathrm{cm}^{3}\right)$ and cellulose $\left(1.5 \mathrm{~g} / \mathrm{cm}^{3}\right)$, weight fractions were converted to volume fractions using Eq. 4 since $\Phi \ll 1$. The aspect ratios were then estimated from the crowding number theory (CNT) and the effective medium theory (EMT) using Eqs. 5 and 6 respectively, as adopted by Varanasi et al. (2013) and Zhang et al. (2012) for CNF materials.

$\Phi=C\left(\rho_{l} / \rho_{f}\right)$

$A=4.9 \Phi_{c}^{-0.5}$

$A=2.52 \Phi_{c}^{-0.58}$

here $\Phi$ is the volume fraction, $\rho_{l}$ is the density of liquid, $\rho_{f}$ is the density of fibre, $C$ is the weight fraction ( $\mathrm{g}$ of fibre/g of suspension), $A$ is the aspect ratio, $\Phi_{c}$ is the connectivity threshold in volume fraction.

\section{Rheological analysis}

Rheological measurements were conducted on all the pre-treated samples to investigate the linear viscoelastic properties of aqueous suspensions of the resulting CNFs. The depletion of particles in suspension from the geometry wall during rheological measurements, known as wall slip, has been shown to be predominant when cone and plate, or plate and plate, geometries are used (Nechyporchuk et al. 2016b). In order to avoid wall slip during the rheological measurements of the CNF suspensions, a serrated concentric cylinder geometry ( $24 \mathrm{~mm}$ inner and $26 \mathrm{~mm}$ outer diameters) was used on AR-G2 rheometer (TA instruments, USA). A peak hold experiment was first carried out for $100 \mathrm{~s}$ at $100 \mathrm{~s}^{-1}$ strain rate to clear the sample history and effects of sample loading, ensuring that the samples tested all had similar starting 'states' and shear history. This was followed by a time sweep, where the temporal evolution of storage modulus $\left(G^{\prime}\right.$, the elastic component) was observed. The duration of the time sweep was carried out up to an equilibrium state where the change in $G^{\prime}$ does not experience a $2 \%$ change over $100 \mathrm{~s}$. This criterion was to ensure that there was minimal change in material properties occurring during the $100 \mathrm{~s}$ experimental duration required for amplitude and frequency sweeps.

An amplitude sweep was then conducted to determine the linear viscoelastic region (LVR). This is the region where the microstructural response, and associated viscoelastic properties, of a material are independent of the degree of deformation imposed (Barnes 2000; Goodwin and Hughes 2008). The critical strain was determined from the amplitude sweep as the strain value at the end point of the LVR before non-linearity in material response sets in (Goodwin and Hughes 2008). The material structure was allowed to recover through another peak hold and time sweep experiments before the frequency sweeps were carried out. Covers were used throughout the experiments to minimise water evaporation from the samples.

\section{Results and discussion}

Swelling studies and CNF production from morpholine pre-treated cellulose

Cellulose fibre swelling is desired to facilitate fibre fibrillation and to reduce the energy cost demand on CNF production. The swelling potential of morpholine on cellulose in different aqueous molar fractions was investigated in this study. A nonlinear relationship can be seen to exist between the mole fraction of morpholine to water and the swelling index of MCC as shown in Fig. 1. The swelling index of MCC increased up to a maximum at 0.7 mole fraction (91 wt \%) before a decline was observed. It is worth noting that morpholine-water mixtures exhibit similar nonlinear relationships with regards to specific gravity, viscosity, and depression in freezing point, with maxima/minima observed at varying concentrations of morpholine with water (Huntsman 2005). Therefore, there is a synergistic relationship between morpholine and water, which is observed in its ability to swell MCC at various aqueous morpholine concentrations. Indeed, there is a $13 \%$ increase in the swelling index from 0.5 to 0.7 mole fraction (83-91 wt\%). However, this difference may not significantly affect the properties of the CNF on a large scale. Moreover, the flashpoint of morpholine at $83 \mathrm{wt} \%$ is higher than that of $91 \mathrm{wt} \%$ and may not require fire proofed 


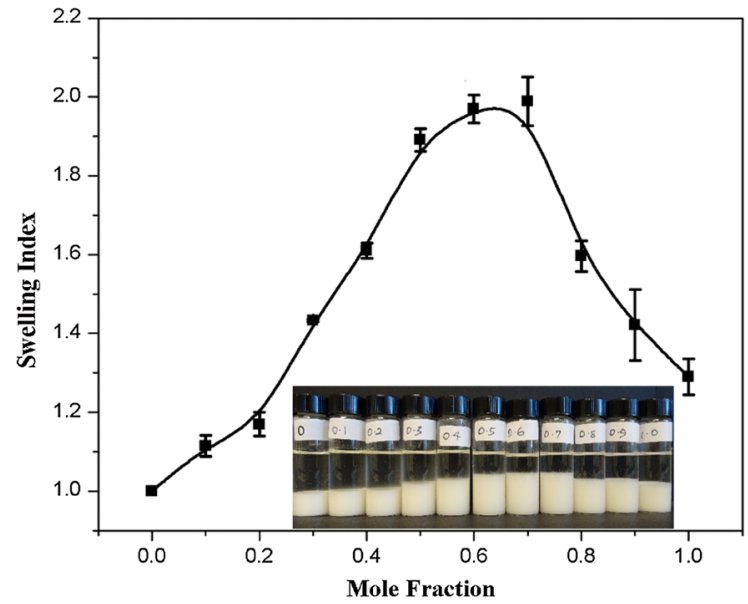

Fig. 1 The relationship between swelling index and mole fraction of morpholine to water, and photographic insert of swelling

processing equipment (HSE 2013). Henceforth, results discussed herein are for CNF pre-treated with $83 \mathrm{wt} \%$ morpholine.

The clogging of the interaction chamber during high pressure processing is one of the challenges frequently encountered during fibrillation of nonpretreated cellulose (Pääkkö et al. 2007), hence the various mechanical and chemical pre-treatments employed to ease fibrillation. Morpholine pre-treatment, just like the carboxymethylation and TEMPOoxidation pre-treatments, was able to effectively swell the cellulose fibres, thereby facilitating the processing of these fibres into nanofibrils and eliminating down time due to interaction chamber clogging issues.

Regarding the energy consumption associated with the mechanical processing using the Microfluidiser, there is no agreement on the methodology used for the calculation of energy consumption in literature. Spence et al. (2011) and Panagiotou et al. (2009) mentioned the energy calculations were provided by Microfluidics Inc. but the details of the calculations were not given. An attempt was made by Luo et al. (2010) to calculate the energy consumed for the largescale production of single walled carbon nanotubes using the Microfluidiser by applying a flawed equation, where the energy consumption is dependent on the square of volume. Moreover, the turbulent energy dissipation rate $(\varepsilon)$, cannot be considered a constant as they stated, but is a function of the processing conditions. The correct form of the equation is given in Eq. 7.
$E_{m}=\varepsilon \frac{\rho V}{1000} t_{\text {res }}$

where $E_{m}$ is the total energy consumed, $\varepsilon$ is the turbulent energy dissipation rate, $V$ is the volume processed, $\rho$ is the density of the dispersion and $t_{\text {res }}$ is the residence time.

On the other hand, the equation provided by Ankerfors (2012) as shown in Eq. 8, based on the transport phenomena-the Bernouli equation, relates the energy consumption to the pressure drop in the Microfluidiser.

$\frac{1}{\rho}\left(p_{2}-p_{1}\right)+w_{\text {pump }}=0$

where $\rho$ is the density of the dispersion, $p_{2}$ is the atmospheric pressure, $p_{1}$ is the processing pressure and $w_{\text {pump }}$ is the work performed.

Equation 8 therefore allows for a comparison of the energy consumption across literature, since most of the work conducted using the Microfluidiser state the processing conditions. It is interesting to note how the pressure drop in Eq. 8 is related to the inverse of density. In other words, processing of cellulose in a solvent of higher density should result in a reduced energy consumption, for a fixed pressure drop. Morpholine exhibits a near maximum density of $1.033 \mathrm{~g} /$ $\mathrm{cm}^{3}$ at the concentration used in this study (Huntsman 2005) and therefore should have a reduced energy demand compared to the carboxymethylated and TEMPO oxidised cellulose processed in water, at the same processing conditions. However, the true cost of production is dependent not only on the energy requirements of the processing conditions but also on the operating costs associated with the equipment.

Surface charge analysis

The effect of the pre-treatments on the total surface charge of the cellulose was studied by conductometric titration and the results obtained from the analysis of the conductometric curves are tabulated in Table 1. On comparing the surface charge of the cellulose starting material with the morpholine pre-treated cellulose (30 and $37 \mu \mathrm{mol} / \mathrm{g}$ respectively), the morpholine pre-treatment did not significantly modify the surface of the cellulose. On the other hand, the carboxymethylation and TEMPO oxidation pre-treatments are known to impact negatively charged 
Table 1 Summary of results from conductometric titration and XRD

\begin{tabular}{lcc}
\hline Sample & Average surface charge $(\mu \mathrm{mol} / \mathrm{g})$ & Crystallinity index $(\%)$ \\
\hline Cellulose pulp & $30 \pm 0$ & 55.1 \\
Morpholine pre-treated cellulose & $37 \pm 6$ & 48.1 \\
Carboxymethylated cellulose & $550 \pm 4$ & 36.0 \\
TEMPO-oxidised cellulose & $1063 \pm 16$ & 39.7 \\
\hline
\end{tabular}

carboxymethyl $\left(\mathrm{CH}_{2} \mathrm{COO}^{-}\right)$and carboxyl $\left(\mathrm{COO}^{-}\right)$ groups respectively to the surface of the cellulose fibre.

The total surface charge for the carboxymethylated $\mathrm{CNF}$ is lower than that of the TEMPO-oxidised CNF for the experimental conditions applied. These results are within literature reported values of 515-610 $\mu \mathrm{mol} /$ $\mathrm{g}$ for carboxymethylated cellulose (Naderi et al. 2014; Siró et al. 2011; Wågberg et al. 2008) and 500-1500 $\mu \mathrm{mol} / \mathrm{g}$ for TEMPO-oxidised CNF (Benhamou et al. 2014; Fukuzumi et al. 2009). The differences in the starting material, amount of reagent, time of reaction, temperature and $\mathrm{pH}$ contribute to the variations in total charged groups reported in literature. These variations in total charged groups often result in differences in the CNF material properties, thereby making comparison of results across literature difficult.

\section{Surface chemistry from FTIR analysis}

In addition to the surface charge analysis by conductometry, the effect of the pre-treatments on the cellulose fibre surface chemistry was probed using FTIR spectroscopy. The overlay of the spectrum of the original cellulose starting material and the pre-treated CNFs is shown in Fig. 2. Three common peaks can be identified from the original cellulose and the pretreated cellulose. These are the peaks within $3335-3338 \mathrm{~cm}^{-1}$, assigned to $\mathrm{O}-\mathrm{H}$ stretching, 2896-2902 $\mathrm{cm}^{-1}$, assigned to $\mathrm{C}-\mathrm{H}$ stretching and $1019 \mathrm{~cm}^{-1}-1029 \mathrm{~cm}^{-1}$, assigned to $\mathrm{C}-\mathrm{O}$ stretching. The peak observed at 1592 and $1603 \mathrm{~cm}^{-1}$ were assigned to $\mathrm{COO}^{-}$stretching in sodium form (Eyholzer et al. 2010). These latter peaks prove the attachment of carboxymethyl and carboxyl groups respectively. It can also be seen that the spectrum and peaks of the morpholine pre-treated CNF clearly overlaps the original cellulose. This shows that no surface modification had taken place after the

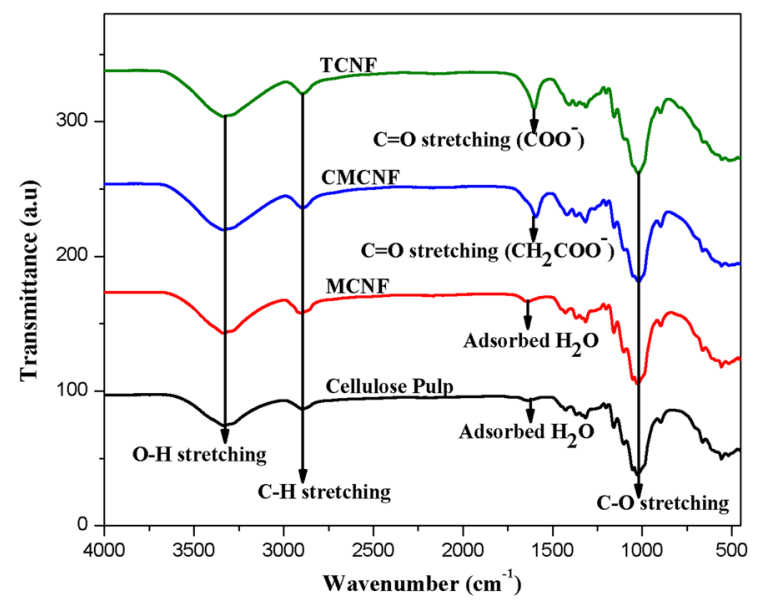

Fig. 2 FTIR overlay of the starting cellulose pulp and the pretreated celluloses

morpholine pre-treatment as also observed from conductometric titration analysis.

Effect of chemical pre-treatments and mechanical processing on cellulose nanofibrils' crystallinity

The crystallinity index of cellulose has been shown to be affected by chemical and mechanical interventions (Eyholzer et al. 2010; Jonoobi et al. 2015; Taheri and Samyn 2016; Tian et al. 2016). The effects of the chemical pre-treatments and mechanical processing on the resulting $\mathrm{CNF}$ materials were investigated using X-ray diffraction. The crystallinity indices of the pre-treated and mechanically fibrillated CNFs are displayed in Table 1 while the overlay of the crystallograms is shown in Fig. 3. All the chemical pretreatments processes used in this study preserved the native cellulose I structure of the fibres. A minor reduction in the intensity of the (1-10)/(110) and (200) crystallographic planes can be identified for MCNF in comparison to those observed for CMCNF and TCNF. Reduction in the intensities of these planes have been shown to be associated with high degree of chemical and mechanical processing (Eyholzer et al. 2010; Su 


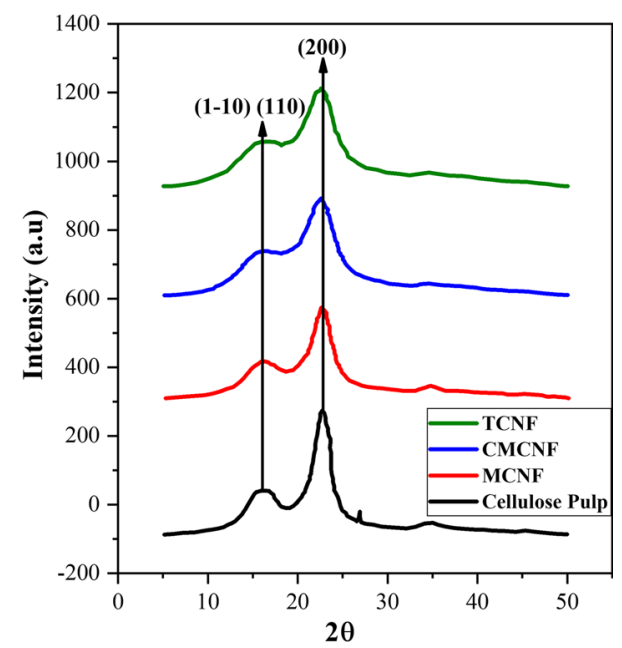

Fig. 3 Overlay of crystallograms from XRD analysis

et al. 2015). Also, the morpholine pre-treatment process did not lead to a marked reduction in crystallinity index and the $13 \%$ decrease observed in comparison to the starting pulp can be attributed to the impact of mechanical shearing (Eyholzer et al. 2010; Taheri and Samyn 2016; Tian et al. 2016). This result is broadly consistent with the surface chemistry analysis reported in previous studies where morpholine was shown not to affect the crystallinity index of cellulose but to only act as an inter-crystalline swelling agent (Betrabet et al. 1966; Betrabet and Rollins 1970; Lokhande 1978; Lokhande et al. 1984).

In contrast, the carboxymethylation pre-treatment process, coupled with mechanical shearing, led to a $35 \%$ decrease in the crystallinity index of $\mathrm{CMCNF}$ compared with the starting cellulose pulp. This observation is similar to that of Eyholzer et al. (2010) whose CNF sample showed a $31 \%$ decrease in crystallinity index after carboxymethylation followed by mechanical homogenisation. However, another study reported no reduction in the crystallinity of carboxymethylated CNF films after multiple homogenisation steps (Siró et al. 2011). This latter report omitted to note the crystallinity of the starting cellulose material to allow for a clearer comparison to be made. The percentage decrease in the crystallinity index of TCNF with respect to the cellulose starting material was however $28 \%$. This smaller reduction in the crystallinity index of TCNF in comparison with CMCNF can be attributed to the selective oxidation of the hydroxyl group on C6 carbon alone (Isogai et al.
2011). The carboxymethylation process on the other hand, being non-selective, can access the hydroxyl groups on carbon $\mathrm{C} 2, \mathrm{C} 3$ and $\mathrm{C} 6$, thereby leading to the observed reduction in crystallinity index (Eyholzer et al. 2010).

Effect of chemical pre-treatments and mechanical processing on cellulose nanofibrils' thermal stability

An understanding of the thermal integrity of CNF materials that may be incorporated as reinforcements in the melt processing of polymer materials is important (Qua et al. 2011). The thermal stabilities of CNF materials can be affected by the pre-treatments and processing conditions and are often directly related to crystallinity. Possible changes in thermal stabilities of the CNF materials were investigated by thermogravimetric analysis. For the sake of clarity, the initial weight loss occurring below $100{ }^{\circ} \mathrm{C}$ because of moisture desorption was not included in the TGA and derivative thermogravimetric (DTG) curves of the pre-treated samples shown in Fig. 4.

The CNF obtained after the morpholine pre-treatment process retained its thermal integrity. This can be seen from the overlap of the TGA and DTG curves of MCNF with that of cellulose pulp, as shown in Fig. 4A and $\mathrm{B}$ respectively. This result also agrees with the results obtained from surface charge analysis, FTIR and XRD measurements. On the other hand, a lower peak degradation temperature was observed for the $\mathrm{CMCNF}$ and much lower peak degradation temperature for the TCNF, when these samples are compared with the cellulose pulp. This is as a result of the presence of sodium carboxymethyl functional group, which has been shown to catalyse the degradation of carboxymethyl cellulose (de Britto and Assis 2009). As mentioned at the beginning of this section, increase or decrease in crystallinity index is expected to be directly related to the thermal integrity of a polymer material. This was not the case however for TCNF, though it had a slightly higher crystallinity index than CMCNF. The presence of sodium anhydroglucuronate units on the surface of TCNF led to the early degradation peak observed at $247{ }^{\circ} \mathrm{C}$ (Fukuzumi et al. 2010; Lavoine et al. 2016; Sharma and Varma 2014). The rest of the unmodified portions of TCNF are then seen to degrade at a higher temperature of $301{ }^{\circ} \mathrm{C}$. 

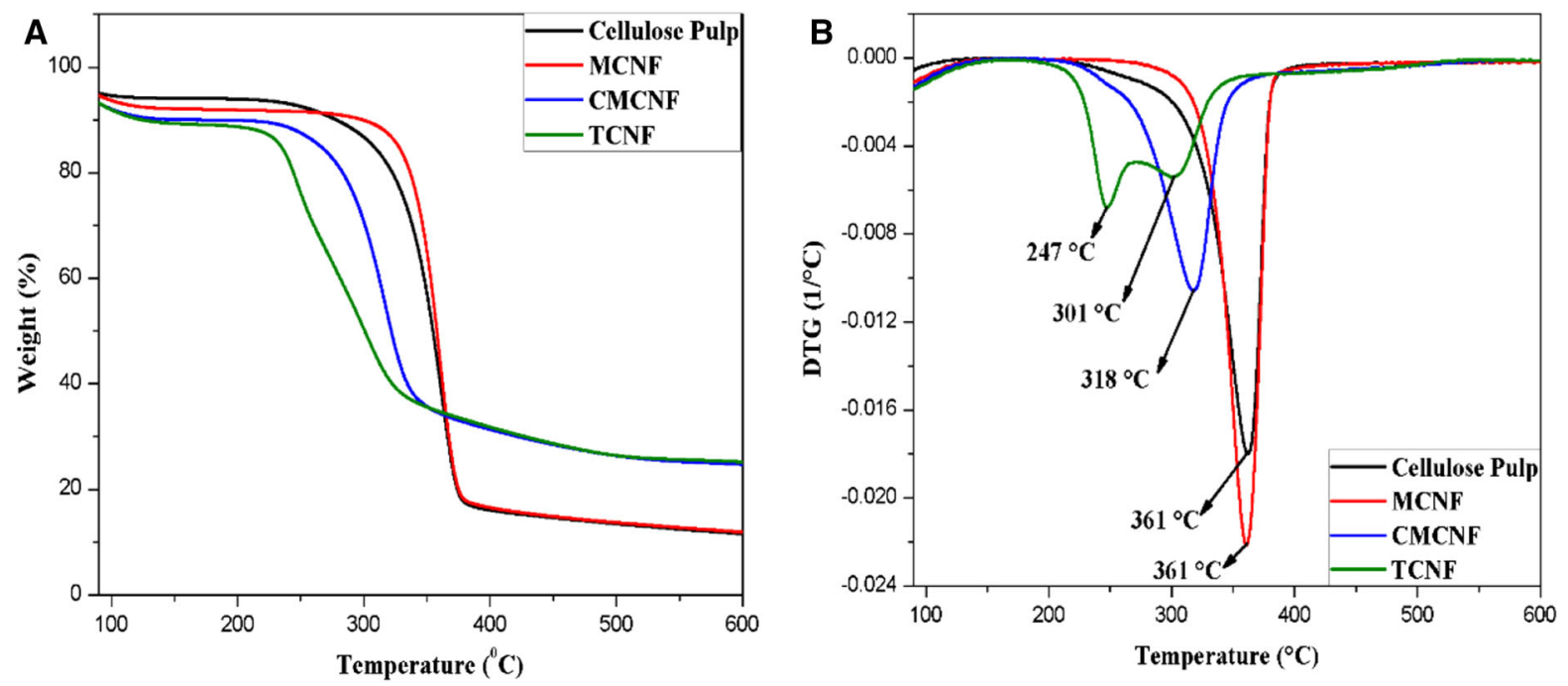

Fig. 4 TGA (A) and DTG (B) overlay of the cellulose pulp and the pre-treated CNFs

Cellulose nanofibril morphology

Field emission scanning electron microscopic images and the fibril width distributions of all the CNFs are shown in Fig. 5. The respective average fibril width from the FE-SEM images of MCNF, CMCNF and TCNF are $15 \pm 11 \mathrm{~nm}, 11 \pm 3 \mathrm{~nm}$ and $9 \pm 2 \mathrm{~nm}$. It can be seen from the fibril width distribution that the morpholine pre-treated CNF had a more polydisperse fibril width distribution in comparison to the carboxymethylated CNF and the TEMPO-oxidised CNF. A relatively small number of wider fibrils, with widths within 40-90 nm, can be seen from the MCNF width distribution. These larger fibrils are only $5 \%$ of the measured fibrils and can still be regarded as nanofibrils, since they are within the $100 \mathrm{~nm}$ limit for nanomaterials (Klaessig et al. 2011). The presence of few larger fibrils is not uncommon for CNFs which do not have any surface electrostatic repulsive force to counter the effect of hydrogen bonding and hydrophobic forces (Sacui et al. 2014; Taheri and Samyn 2016). Therefore CNFs from enzymatic pre-treatments (Sacui et al. 2014) and mechanical processes (Taheri and Samyn 2016) often possess larger fibrils and flocs which are surrounded by large amounts cellulose nanofibrils.

TEM images of the CNFs are shown in Fig. 6 alongside their fibril width distribution. The trend in the size of fibril widths observed from FE-SEM images can also be seen with the TEM images of the pre-treated CNFs. The MCNF, CMCNF and TCNF material had a respective fibril width of $8 \pm 4 \mathrm{~nm}$, $6 \pm 2 \mathrm{~nm}$ and $5 \pm 2 \mathrm{~nm}$. These values are within the TEM values of 5-15 nm reported for carboxymethylated CNF (Wågberg et al. 2008) and the 3 to $5 \mathrm{~nm}$ widths reported for TEMPO-oxidised CNFs (Isogai et al. 2011). For all the CNFs, the fibril widths from TEM images are lower than those obtained from FESEM images. This is because of the lower resolution of FE-SEM images compared to those from TEM. The highly resolved TEM images are capable of distinguishing elemental fibrils from bundles of fibrils, hence the lower value obtained (Dufresne 2012; Wang et al. 2012).

The overall morphologies of the CNFs studied herein are those of an entangled and networked structure, even at the low concentration of CNFs used in the sample preparation for both the FE-SEM and TEM studies. Therefore, the measurement of fibril lengths from the microscopic images of these samples could not be carried out.

Aspect ratio determination from sedimentation

The use of sedimentation for aspect ratio estimation has been applied on uncharged and unmodified CNFs (Raj et al. 2016; Varanasi et al. 2013; Zhang et al. 2012). It was suggested as a facile method for the quality control of CNF materials during processing (Raj et al. 2016). This method was herein adapted for 

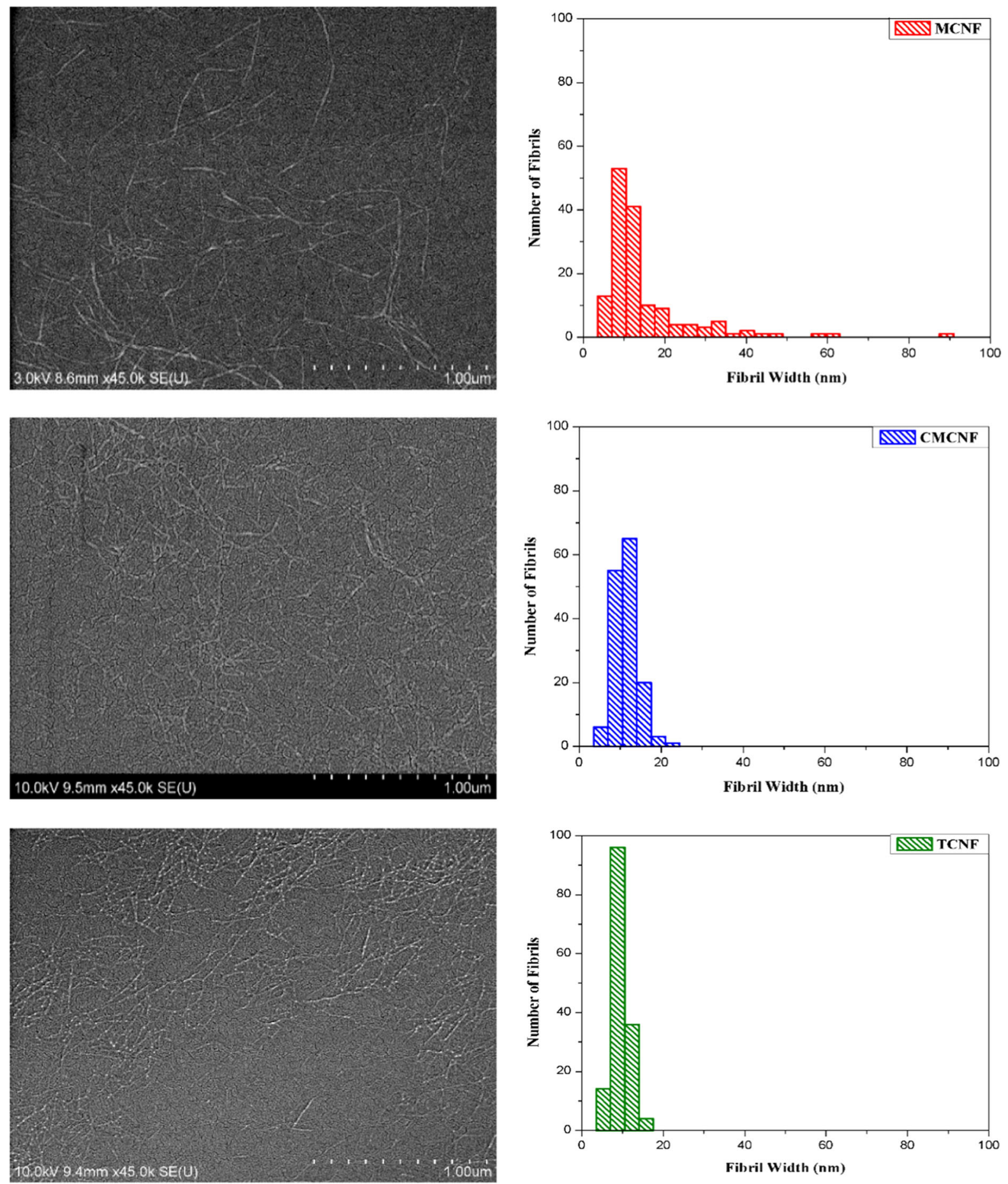

Fig. 5 FE-SEM micrographs and fibril width distribution of MCNF, CMCNF and TCNF

electrostatically stabilised $\mathrm{CMCNF}$ and TCNF to estimate their aspect ratios. On increasing the ionic strength of a medium, its Debye length, which is the distance at which the surface potential decreases by $1 /$ eth of its value, would be decreased. This would lead to a dampening or screening of the charges on the 

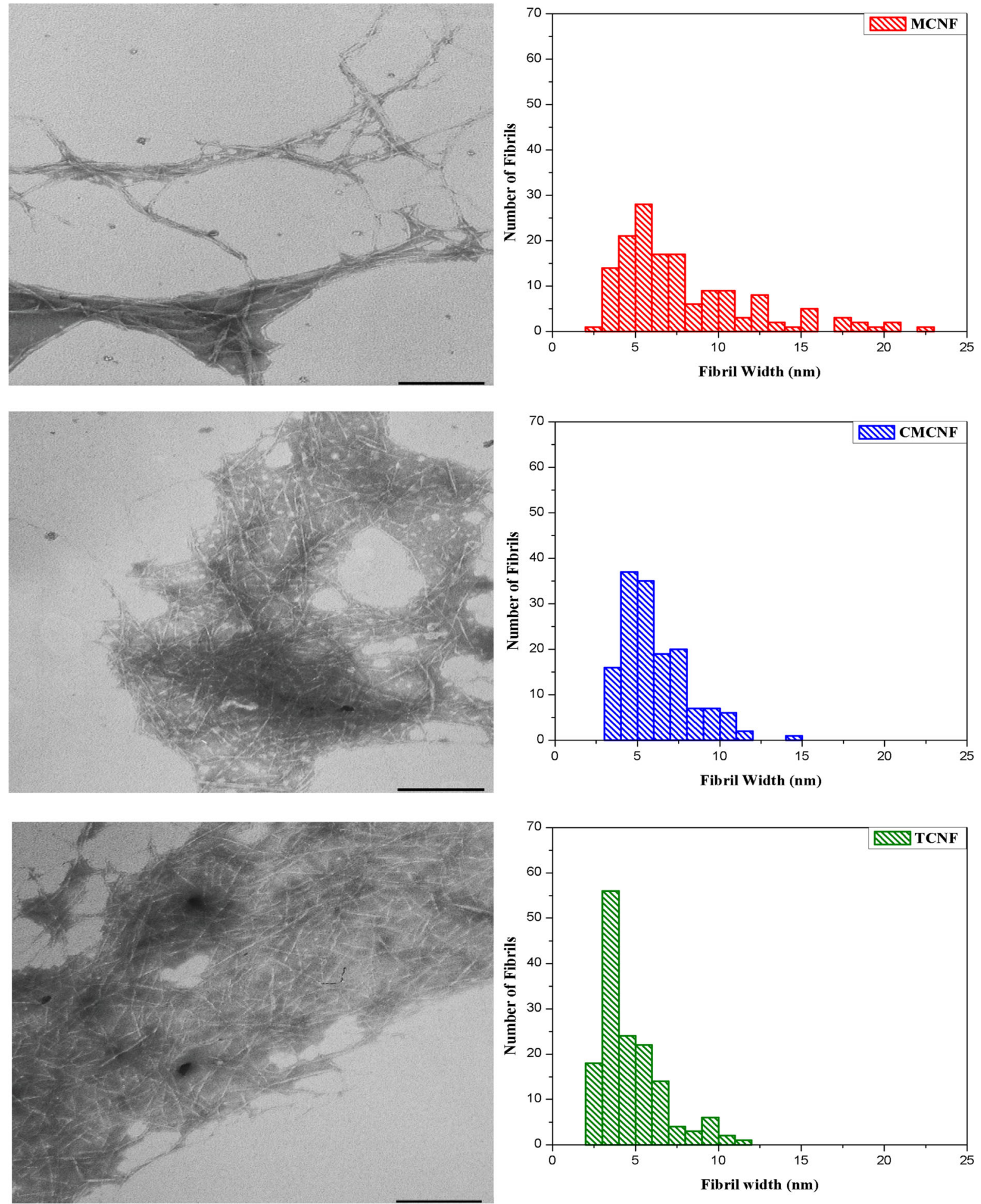

Fig. 6 TEM images and fibril width distributions of MCNF, CMCNF and TCNF. Scale bar $=227 \mathrm{~nm}$ 
particles in the medium, giving rise to particle aggregation. The aggregation and subsequent sedimentation of the ionically stabilised CMCNF and TCNF was made possible after screening the CNFs in 2 and 3 M sodium chloride respectively (see Fig. 7 for photographic images of sedimentation).

The plots of initial concentration of the CNFs in $\mathrm{wt} \%$ as a function of the relative sediment height $\left(h_{s} /\right.$ $h_{0}$ ) in water/salt media are shown in Fig. 8. The linear component of this fit, which is equivalent to the connectivity threshold was inputted into the crowding number and effective medium equations (Eqs. 5,6) to calculate the aspect ratios of the CNFs shown in Table 2. It can be seen from Table 2 that MCNF had a lower estimated aspect ratio than CMCNF, with TCNF having the highest estimated aspect ratio.

Before a logical conclusion can be drawn, it is necessary to point out the polydispersity of MCNF

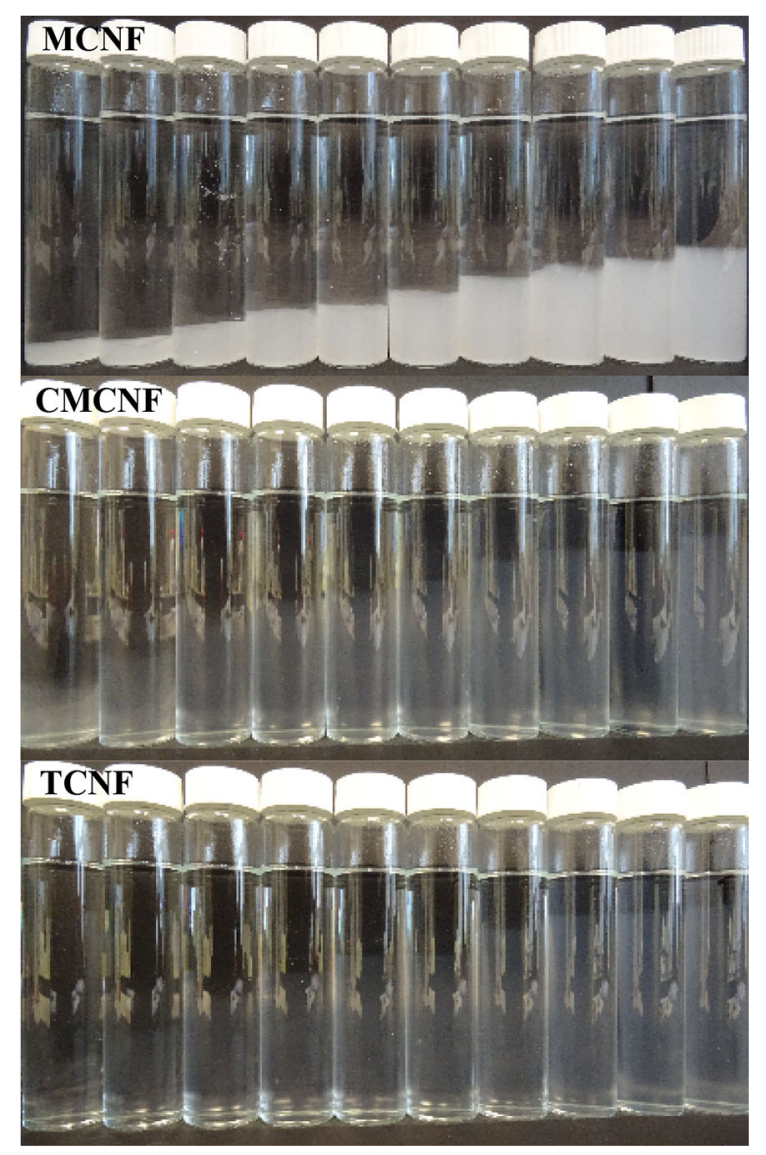

Fig. 7 Photographic images of sedimentation experiment of the MCNF in water, $\mathrm{CMCNF}$ and TCNF in 2 and $3 \mathrm{M} \mathrm{NaCl}$ respectively

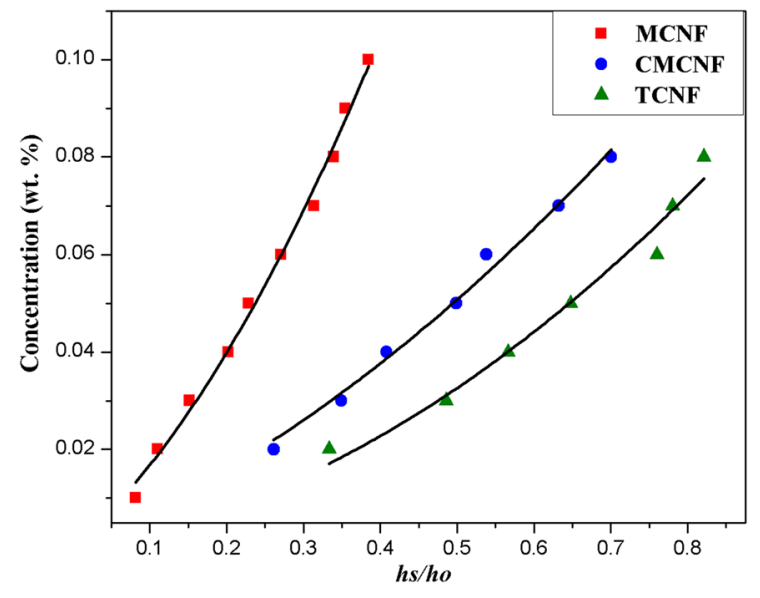

Fig. 8 Quadratic fit of relative sediment height against initial concentration

fibril width as shown in Figs. 5 and 6 and its possible effect on sedimentation. Since this method involved the settling of fibrils in a suspension under gravity, it is expected that suspensions with larger/flocculated fibrils, will settle at a faster rate than the individual nanofibrils (differential sedimentation) (Gregory 2013). These flocs can potentially also drag with them the thin interconnected nanofibrils, leading to a lower relative sediment height (higher connectivity threshold) at the concentrations examined; hence the lower aspect ratio observed for the morpholine pre-treated CNF. On the other hand, the CMCNF and TCNF materials which do not possess larger fibrils, based on the FE-SEM and TEM width distribution, would settle at a uniform rate. Therefore, differential sedimentation would not be an issue for these materials, thereby giving their true aspect ratios.

The estimated CNT aspect ratio is higher than EMT aspect ratio only when the connectivity threshold in volume fraction is greater than $2.45 \times 10^{-4}$. Thus, the CNT aspect ratio is higher than EMT aspect ratio for MCNF and CMCNF, but lower for TCNF. The estimated aspect ratio of MCNF was 33\% higher than the aspect ratio of unmodified filtered cellulose nanofibril reported by Varanasi et al. (2013), using the same sedimentation approach. The aspect ratio of the TEMPO-oxidised CNF reported in this study falls within the range of 310-623 reported for those measured from shear viscosity length measurements (Tanaka et al. 2014). 
Table 2 Sedimentation results obtained from quadratic regression fits

\begin{tabular}{|c|c|c|c|c|c|}
\hline Sample & Quadratic regression & $\begin{array}{l}\text { Connectivity threshold (wt. } \\
\text { fraction) }\end{array}$ & $\begin{array}{l}\text { Connectivity threshold (vol. } \\
\text { fraction) }\end{array}$ & $\begin{array}{l}\mathrm{CNT} \text { aspect } \\
\text { ratio }\end{array}$ & $\begin{array}{l}\text { EMT aspect } \\
\text { ratio }\end{array}$ \\
\hline MCNF & $\begin{array}{l}\mathrm{y}=0.3 x^{2}+0.14 x \\
R^{2}=0.99\end{array}$ & 0.0014 & 0.00093 & $161 \pm 2$ & $144 \pm 2$ \\
\hline CMCNF & $\begin{array}{l}\mathrm{y}=0.07 x^{2}+0.065 x \\
R^{2}=0.98\end{array}$ & 0.00065 & 0.00046 & $229 \pm 18$ & $217 \pm 18$ \\
\hline TCNF & $\begin{array}{l}\mathrm{y}=0.08 x^{2}+0.02 x \\
R^{2}=0.97\end{array}$ & 0.0002 & 0.00015 & $400 \pm 30$ & $416 \pm 30$ \\
\hline
\end{tabular}

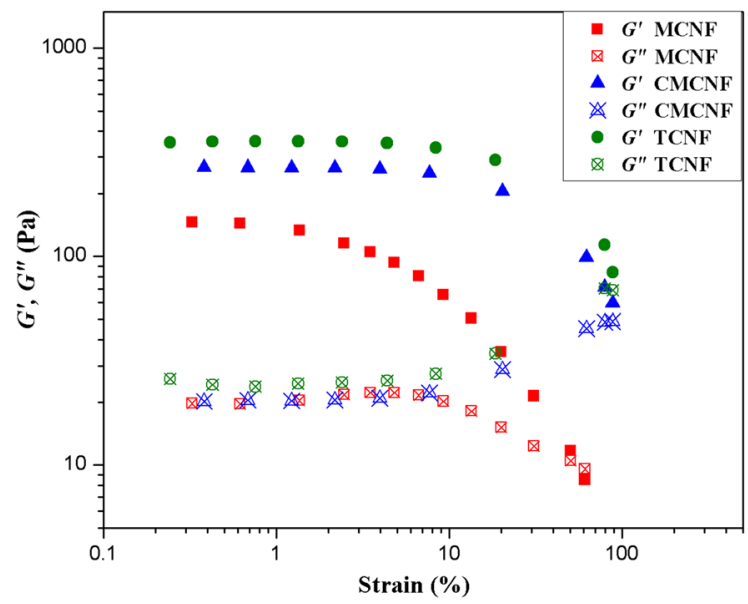

Fig. 9 An overlay of amplitude sweeps from all the pre-treated CNFs

Rheological analysis

The overlay of the amplitude sweeps obtained from all the pre-treated cellulose nanofibrils at $1 \mathrm{wt} \%$ aqueous suspension is shown in Fig. 9. All the pre-treated CNFs showed higher $G^{\prime}$ (the elastic component at any frequency) than $G^{\prime \prime}$ (the viscous component at any frequency). The value of $G^{\prime}$ within the LVR and the critical strain was lower for the MCNF than for the CMCNF and TCNF as displayed in Table 3. This behaviour is expected as the viscoelastic properties of the morpholine pre-treated sample is governed by the physical entanglements and the presence of network of fibrils, brought about by the Van der Waals forces acting on the fibrils, rather than electrostatic repulsive forces. The viscoelastic properties of the CMCNF and TCNF are however controlled by the presence of electrostatic repulsive forces on the surface of the fibrils, physical entanglements and Van der Waals forces (Lasseuguette et al. 2007; Lindström 2017; Naderi et al. 2014). These are coupled with the lower rigidity threshold (wt\%) of the charged CNFs. In theory, the implication would be that while the viscoelastic property of MCNF was measured at 1.8 times its rigidity threshold, that of CMCNF and TCNF were respectively measured at 3.8 and 12.5 times their rigidity thresholds.

The trend observed from the amplitude sweep was also seen in the frequency sweep, with the morpholine pre-treated CNF having a lower $G^{\prime}$ value compared to the charged CNFs as shown in Fig. 10. The storage moduli were relatively independent of angular frequency for all the pre-treated CNFs. Also, the loss value $\left(\tan \delta=G^{\prime \prime} / G^{\prime}\right.$ ) of all the pre-treated CNFs, as shown in Table 3, is much less than 1 . These results confirm the predominantly elastic nature of the aqueous $\mathrm{CNF}$ suspensions $\left(\delta \leq 10^{\circ}\right)$, since purely elastic materials are expected to be independent of frequency (Pääkkö et al. 2007).

Table 3 Summary of rheological data from the pre-treated CNFs at $1 \mathrm{wt} \%$ solid concentration

\begin{tabular}{lllll}
\hline Sample & Rigidity threshold $\left(4 \mathrm{x} \Phi_{\mathrm{c}}, \mathrm{wt} \%\right)$ & $G^{\prime}(\mathrm{Pa})$ at $0.3-0.4 \%$ strain & Critical strain $(\%)$ & $\tan \delta \mathrm{at}^{2} \mathrm{rads}^{-1}$ \\
\hline MCNF & 0.56 & 146 & 0.7 & 0.16 \\
CMCNF & 0.26 & 268 & 5.4 & 0.08 \\
TCNF & 0.08 & 356 & 5.7 & 0.07 \\
\hline
\end{tabular}




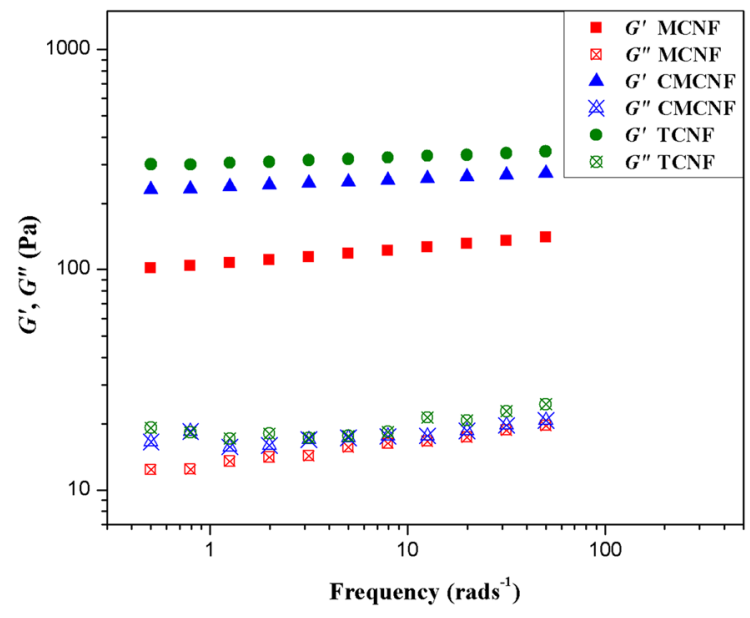

Fig. 10 An overlay of frequency sweeps from all the pretreated CNFs

\section{Conclusions}

The properties of CNF materials obtained from morpholine pre-treatment have been investigated and compared with the properties of CNFs made from carboxymethylation and TEMPO-oxidation pre-treatments, under the same mechanical processing conditions. Initial swelling of cellulose in various concentrations of morpholine revealed that there is a synergism between morpholine and water, which enhanced the swelling of cellulose. The maximal swelling occurred around the maximum density of the swelling agent, which in turn led to enhanced fibrillation and reduced energy consumption, based on hydrodynamic considerations. Surface chemistry analyses, crystallinity and thermogravimetric measurements indicated that morpholine pre-treatment did not modify the surface of cellulose, in contrast to the carboxymethylation and TEMPO-oxidation processes which attached anionic groups to the cellulose surface. The fibril widths of the MCNFs are broadly similar to those of the CMCNF and TCNF, while the lower estimated aspect ratio of the MCNFs compared to CMCNF and TCNF can be attributed to the possible differential sedimentation of fibrils due to the presence of few larger fibrils. The presence of electrostatic repulsive forces and lower rigidity threshold of the CMCNF and TCNF also resulted in higher viscoelastic moduli $\left(G^{\prime}\right)$ and critical strains compared to MCNF whose viscoelastic behaviour arises from the network entanglements. It has also been demonstrated that the morpholine pre-treatment method uses only one chemical which can be recovered and re-used, compared to the other pre-treatment processes used in this study which make use of greater amounts of chemicals with low potential for recycling. The unmodified MCNF having maintained its crystallinity and thermal stability can find application as polymer reinforcements, as starting materials for acetylation, silylation, and acylation reactions to impart hydrophobic properties, and as structuring materials/rheology modifiers.

Acknowledgments The authors thank the Edinburgh Napier University for the 25th Anniversary Studentship. They are also grateful Sappi Ltd (South Africa) for providing the cellulose starting material, Dr. Roger Ibbett of the School of Biosciences, University of Nottingham for assisting with XRD measurements, Dr Lucia Conzatti of the Consiglio Nazionale Delle Ricerche, Genoa, Italy for the helping with acquiring the TEM images, Prof Silvia Vicini of the Department of Chemistry and Industrial Chemistry, University of Genoa, Italy for assisting with the thermogravimetric analysis.

Open Access This article is distributed under the terms of the Creative Commons Attribution 4.0 International License (http:// creativecommons.org/licenses/by/4.0/), which permits unrestricted use, distribution, and reproduction in any medium, provided you give appropriate credit to the original author(s) and the source, provide a link to the Creative Commons license, and indicate if changes were made.

\section{References}

Abbott AP, Bell TJ, Handa S, Stoddart B (2006) Cationic functionalisation of cellulose using a choline based ionic liquid analogue. Green Chem 8:784-786. https://doi.org/ 10.1039/B605258D

Abdul Khalil HPS, Davoudpour Y, Islam MN, Mustapha A, Sudesh K, Dungani R, Jawaid M (2014) Production and modification of nanofibrillated cellulose using various mechanical processes: a review. Carbohydr Polym 99:649-665. https://doi.org/10.1016/j.carbpol.2013.08. 069

Ankerfors M (2012) Microfibrillated cellulose : energy-efficient preparation techniques and key properties. Licentiate Thesis, Comprehensive Summary, KTH Royal Institute of Technology

Aulin C, Johansson E, Wågberg L, Lindström T (2010) Selforganized films from cellulose I nanofibrils using the layerby-layer technique. Biomacromolecules 11:872-882. https://doi.org/10.1021/bm100075e

Barnes HA (2000) A handbook of elementary rheology. Institute of non-Newtonian fluid mechanics, University of Wales, Aberystwyth

Benhamou K, Dufresne A, Magnin A, Mortha G, Kaddami H (2014) Control of size and viscoelastic properties of 
nanofibrillated cellulose from palm tree by varying the TEMPO-mediated oxidation time. Carbohydr Polym 99:74-83. https://doi.org/10.1016/j.carbpol.2013.08.032

Berglund L, Anugwom I, Hedenström M, Aitomäki Y, Mikkola J-P, Oksman K (2017) Switchable ionic liquids enable efficient nanofibrillation of wood pulp. Cellulose 24:3265-3279. https://doi.org/10.1007/s10570-017-13542

Betrabet SM, Rollins ML (1970) Electron-microscope study of cotton treated with inter- and intracrystalline swelling agents. Text Res J 40:917-924. https://doi.org/10.1177/ 004051757004001008

Betrabet SM, Daruwalla EH, Lokhande HT (1966) Intercrystalline swelling in morpholine-treated cotton cellulose. Text Res J 36:684-686. https://doi.org/10.1177/ 004051756603600715

Bharimalla AK, Deshmukh SP, Patil PG, Vigneshwaran N (2015) Energy efficient manufacturing of nanocellulose by chemo- and bio-mechanical processes: a review. World J Nano Sci Eng 5:204-212

Carrillo CA, Laine J, Rojas OJ (2014) Microemulsion systems for fiber deconstruction into cellulose nanofibrils. ACS Appl Mater Interfaces 6:22622-22627. https://doi.org/10. 1021/am5067332

Celzard A, Fierro V, Kerekes R (2009) Flocculation of cellulose fibres: new comparison of crowding factor with percolation and effective-medium theories. Cellulose 16:983. https:// doi.org/10.1007/s10570-009-9314-0

de Britto D, Assis OBG (2009) Thermal degradation of carboxymethylcellulose in different salty forms. Thermochim Acta 494:115-122. https://doi.org/10.1016/j.tca.2009.04. 028

Deng S, Huang R, Zhou M, Chen F, Fu Q (2016) Hydrophobic cellulose films with excellent strength and toughness via ball milling activated acylation of microfibrillated cellulose. Carbohydr Polym 154:129-138. https://doi.org/10. 1016/j.carbpol.2016.07.101

HSE (2013) Dangerous substances and explosive atmospheres regulations (DSEAR). 2nd edn, Crown New York

Du X, Zhang Z, Liu W, Deng Y (2017) Nanocellulose-based conductive materials and their emerging applications in energy devices-a review. Nano Energy 35:299-320. https://doi.org/10.1016/j.nanoen.2017.04.001

Dufresne A (2012) Nanocellulose: from nature to high performance tailored materials, vol 1. Aufl., vol Book, Whole. Berlin

Eyholzer C et al (2010) Preparation and characterization of water-redispersible nanofibrillated cellulose in powder form. Cellulose 17:19-30. https://doi.org/10.1007/s10570009-9372-3

Eyley S, Thielemans W (2014) Surface modification of cellulose nanocrystals. Nanoscale 6:7764-7779. https://doi.org/10. 1039/C4NR01756K

Faruk O, Sain M, Farnood R, Pan Y, Xiao H (2014) Development of lignin and nanocellulose enhanced bio PU foams for automotive parts. J Polym Environ 22:279-288. https:// doi.org/10.1007/s10924-013-0631-x

Ferrer A, Pal L, Hubbe M (2017) Nanocellulose in packaging: advances in barrier layer technologies. Ind Crops Prod 95:574-582. https://doi.org/10.1016/j.indcrop.2016.11. 012
French AD (2017) Glucose, not cellobiose, is the repeating unit of cellulose and why that is important. Cellulose 24:4605-4609. https://doi.org/10.1007/s10570-017-14503

Fukuzumi H, Saito T, Iwata T, Kumamoto Y, Isogai A (2009) Transparent and high gas barrier films of cellulose nanofibers prepared by TEMPO-mediated oxidation. Biomacromolecules 10:162-165. https://doi.org/10.1021/ bm801065u

Fukuzumi H, Saito T, Okita Y, Isogai A (2010) Thermal stabilization of TEMPO-oxidized cellulose. Polym Degrad Stab 95:1502-1508. https://doi.org/10.1016/j.polymdegradstab. 2010.06.015

Goodwin J, Hughes R (2008) Rheology for chemists: an introduction. In: The royal society of chemistry, 2nd edn. Cambridge, pp 92-257. https://doi.org/10.1039/ 9781847558046-00194

Graveson I, English R (2015) Low energy method for the preparation of non-derivatized nanocellulose. Google Patents

Gregory J (2013) Flocculation fundamentals. In: Tadros T (ed) Encyclopedia of colloid and interface science. Springer, Berlin, pp 459-491. https://doi.org/10.1007/978-3-64220665-8_17

Guise C, Fangueiro R (2016) Biomedical applications of nanocellulose. In: Fangueiro R, Rana S (eds) Natural fibres: advances in science and technology towards industrial applications: from science to market. Springer, Dordrecht, pp 155-169. https://doi.org/10.1007/978-94017-7515-1_12

Huntsman (2005) Morpholine. Huntsman Corporation, The Woodlands

Isogai A, Saito T, Fukuzumi H (2011) TEMPO-oxidized cellulose nanofibers. Nanoscale 3:71-85. https://doi.org/10. 1039/C0NR00583E

Jonoobi M, Oladi R, Davoudpour Y, Oksman K, Dufresne A, Hamzeh Y, Davoodi R (2015) Different preparation methods and properties of nanostructured cellulose from various natural resources and residues: a review. Cellulose 22:935-969. https://doi.org/10.1007/s10570-015-0551-0

Klaessig F, Marrapese M, Abe S (2011) Current perspectives in nanotechnology terminology and nomenclature. In: Murashov V, Howard J (eds) Nanotechnology standards. Springer, New York, pp 21-52. https://doi.org/10.1007/ 978-1-4419-7853-0_2

Klemm D, Kramer F, Moritz S, Lindström T, Ankerfors M, Gray D, Dorris A (2011) Nanocelluloses: a new family of naturebased materials. Angew Chem Int Ed 50:5438-5466. https://doi.org/10.1002/anie.201001273

Kulkarni MP, Lokhande HT (1975) Synergism and swelling in morpholine ethylenediamine-treated cotton cellulose. Text Res J 45:108-109. https://doi.org/10.1177/ 004051757504500203

Kuutti L, Pajari H, Rovio S, Kokkonen J, Nuopponen M (2016) Chemical recovery in TEMPO oxidation. Bioresources 11(3):6050-6061

Lasseuguette E, Roux D, Nishiyama Y (2007) Rheological properties of microfibrillar suspension of TEMPO-oxidized pulp. Cellulose 15:425-433. https://doi.org/10.1007/ s10570-007-9184-2 
Lavoine N, Desloges I, Dufresne A, Bras J (2012) Microfibrillated cellulose-its barrier properties and applications in cellulosic materials: a review. Carbohydr Polym 90:735-764. https://doi.org/10.1016/j.carbpol.2012.05. 026

Lavoine N, Bras J, Saito T, Isogai A (2016) Improvement of the thermal stability of TEMPO-oxidized cellulose nanofibrils by heat-induced conversion of ionic bonds to amide bonds. Macromol Rapid Commun. https://doi.org/10.1002/marc. 201600186

Li F, Mascheroni E, Piergiovanni L (2015) The potential of nanocellulose in the packaging field: a review. Packag Technol Sci 28:475-508. https://doi.org/10.1002/pts.2121

Liimatainen H, Visanko M, Sirviö JA, Hormi OEO, Niinimaki J (2012) Enhancement of the nanofibrillation of wood cellulose through sequential periodate-chlorite oxidation. Biomacromolecules 13:1592-1597. https://doi.org/10. 1021/bm300319m

Liimatainen H, Visanko M, Sirviö J, Hormi O, Niinimäki J (2013) Sulfonated cellulose nanofibrils obtained from wood pulp through regioselective oxidative bisulfite pretreatment. Cellulose 20:741-749. https://doi.org/10.1007/ s10570-013-9865-y

Lin N, Dufresne A (2014) Nanocellulose in biomedicine: current status and future prospect. Eur Polym J 59:302-325. https://doi.org/10.1016/j.eurpolymj.2014.07.025

Lindström T (2017) Aspects on nanofibrillated cellulose (NFC) processing, rheology and NFC-film properties. Curr Opin Colloid Interface Sci 29:68-75. https://doi.org/10.1016/j. cocis.2017.02.005

Lokhande HT (1978) Swelling behavior of cotton fibers in morpholine and piperidine. J Appl Polym Sci 22:1243-1253. https://doi.org/10.1002/app.1978. 070220507

Lokhande HT, Sirmour SG, Shukla SR, Sinha SB, Patil NB, Chidambareswaran PK (1984) Swelling of cotton fibers in ethylenediamine-morpholine mixtures. J Appl Polym Sci 29:2421-2429. https://doi.org/10.1002/app.1984. 070290716

Luo S, Liu T, Wang B (2010) Comparison of ultrasonication and microfluidization for high throughput and large-scale processing of SWCNT dispersions. Carbon 48:2992-2994. https://doi.org/10.1016/j.carbon.2010.04.006

Missoum K, Belgacem M, Bras J (2013) Nanofibrillated cellulose surface modification: a review. Materials 6:1745

Naderi A et al (2014) Carboxymethylated nanofibrillated cellulose: rheological studies. Cellulose 21:1561-1571. https://doi.org/10.1007/s10570-014-0192-8

Nechyporchuk O, Belgacem MN, Bras J (2016a) Production of cellulose nanofibrils: a review of recent advances. Ind Crops Prod. https://doi.org/10.1016/j.indcrop.2016.02.016

Nechyporchuk O, Belgacem MN, Pignon F (2016b) Current progress in rheology of cellulose nanofibril suspensions. Biomacromolecules 17:2311-2320. https://doi.org/10. 1021/acs.biomac.6b00668

Pääkkö M et al (2007) Enzymatic hydrolysis combined with mechanical shearing and high-pressure homogenization for nanoscale cellulose fibrils and strong gels. Biomacromolecules 8:1934-1941. https://doi.org/10.1021/ bm061215p
Panagiotou T, Mesite SV, Fisher RJ (2009) Production of norfloxacin nanosuspensions using microfluidics reaction technology through solvent/antisolvent crystallization. Ind Eng Chem Res 48:1761-1771. https://doi.org/10.1021/ ie800955t

Paul R, Teli MD (2011) Effect of swelling and reactive dyeing on the accessibility of cotton to cellulase enzymes. J Appl Polym Sci 121:1946-1950. https://doi.org/10.1002/app. 33772

Qua EH, Hornsby PR, Sharma HSS, Lyons G (2011) Preparation and characterisation of cellulose nanofibres. J Mater Sci 46:6029-6045. https://doi.org/10.1007/s10853-011-5565$\mathrm{X}$

Raj P, Mayahi A, Lahtinen P, Varanasi S, Garnier G, Martin D, Batchelor W (2016) Gel point as a measure of cellulose nanofibre quality and feedstock development with mechanical energy. Cellulose 23:3051-3064. https://doi. org/10.1007/s10570-016-1039-2

Sacui IA et al (2014) Comparison of the properties of cellulose nanocrystals and cellulose nanofibrils isolated from bacteria, tunicate, and wood processed using acid, enzymatic, mechanical, and oxidative methods. ACS Appl Mater Interfaces 6:6127-6138. https://doi.org/10.1021/ am500359f

Saito T, Isogai A (2004) TEMPO-mediated oxidation of native cellulose: the effect of oxidation conditions on chemical and crystal structures of the water-insoluble fractions. Biomacromolecules 5:1983-1989. https://doi.org/10.1021/ bm0497769

Saito T, Kimura S, Nishiyama Y, Isogai A (2007) Cellulose nanofibers prepared by TEMPO-mediated oxidation of native cellulose. Biomacromolecules 8:2485-2491. https:// doi.org/10.1021/bm0703970

Sharma PR, Varma AJ (2014) Functionalized celluloses and their nanoparticles: morphology, thermal properties, and solubility studies. Carbohydr Polym 104:135-142. https:// doi.org/10.1016/j.carbpol.2014.01.015

Shi Z, Phillips GO, Yang G (2013) Nanocellulose electroconductive composites. Nanoscale 5:3194-3201. https://doi. org/10.1039/C3NR00408B

Siró I, Plackett D (2010) Microfibrillated cellulose and new nanocomposite materials: a review. Cellulose 17:459-494. https://doi.org/10.1007/s10570-010-9405-y

Siró I, Plackett D, Hedenqvist M, Ankerfors M, Lindström T (2011) Highly transparent films from carboxymethylated microfibrillated cellulose: the effect of multiple homogenization steps on key properties. J Appl Polym Sci 119:2652-2660. https://doi.org/10.1002/app.32831

Spence KL, Venditti RA, Rojas OJ, Habibi Y, Pawlak JJ (2011) A comparative study of energy consumption and physical properties of microfibrillated cellulose produced by different processing methods. Cellulose 18:1097-1111. https://doi.org/10.1007/s10570-011-9533-z

Su Y, Burger C, Ma H, Chu B, Hsiao BS (2015) Exploring the nature of cellulose microfibrils. Biomacromolecules 16:1201-1209. https://doi.org/10.1021/bm501897z

Taheri H, Samyn P (2016) Effect of homogenization (microfluidization) process parameters in mechanical production of micro- and nanofibrillated cellulose on its rheological and morphological properties. Cellulose. https://doi.org/10.1007/s10570-016-0866-5 
Tanaka R, Saito T, Ishii D, Isogai A (2014) Determination of nanocellulose fibril length by shear viscosity measurement. Cellulose 21:1581-1589. https://doi.org/10.1007/s10570014-0196-4

Tian C, Yi J, Wu Y, Wu Q, Qing Y, Wang L (2016) Preparation of highly charged cellulose nanofibrils using high-pressure homogenization coupled with strong acid hydrolysis pretreatments. Carbohydr Polym 136:485-492. https://doi. org/10.1016/j.carbpol.2015.09.055

Total acidic group content (2002). Scandinavian pulp, paper and board testing committee

Turbak AF, Snyder FW, Sandberg KR (1983a) Microfibrillated cellulose. Google Patents

Turbak AF, Snyder FW, Sandberg KR (1983b) Microfibrillated cellulose, a new cellulose product: properties, uses, and commercial potential. J Appl Polym Sci Appl Polym Symp 37:815-827
Varanasi S, He R, Batchelor W (2013) Estimation of cellulose nanofibre aspect ratio from measurements of fibre suspension gel point. Cellulose 20:1885-1896. https://doi.org/ 10.1007/s10570-013-9972-9

Wågberg L, Decher G, Norgren M, Lindström T, Ankerfors M, Axnäs K (2008) The build-up of polyelectrolyte multilayers of microfibrillated cellulose and cationic polyelectrolytes. Langmuir 24:784-795. https://doi.org/10.1021/la702481v

Wang QQ, Zhu JY, Gleisner R, Kuster TA, Baxa U, McNeil SE (2012) Morphological development of cellulose fibrils of a bleached eucalyptus pulp by mechanical fibrillation. Cellulose 19:1631-1643. https://doi.org/10.1007/s10570-0129745-x

Zhang L, Batchelor W, Varanasi S, Tsuzuki T, Wang X (2012) Effect of cellulose nanofiber dimensions on sheet forming through filtration. Cellulose 19:561-574. https://doi.org/ 10.1007/s10570-011-9641-9 